\title{
Nanostructure-Coated Diclofenac-Loaded Microparticles: Preparation, Morphological Characterization, In Vitro Release and In Vivo Gastrointestinal Tolerance
}

\author{
Ruy C. R. Beck ${ }^{a}$, Adriana R. Pohlmann ${ }^{a, b}$, Edilson V. Benvenutti ${ }^{c}$, Teresa Dalla Costa ${ }^{a}$ \\ and Sílvia S. Guterres ${ }^{*, a}$ \\ ${ }^{a}$ Programa de Pós-Graduação em Ciências Farmacêuticas, Faculdade de Farmácia, Universidade Federal do Rio \\ Grande do Sul, Av. Ipiranga, 1752, 90610-000 Porto Alegre-RS, Brazil \\ ${ }^{b}$ Departamento de Química Orgânica and ${ }^{c}$ Departamento de Química Inorgânica, Instituto de Química, Universidade \\ Federal do Rio Grande do Sul, CP 15003, 91501-970 Porto Alegre- RS, Brazil
}

\begin{abstract}
Micropartículas com revestimento nanoestruturado, contendo diclofenaco, foram preparadas e caracterizadas apresentando um rendimento de $80 \%$ e taxa de encapsulação de $83 \%$. A análise morfológica (MEV) permitiu a visualização de nanoestruturas adsorvidas à superfície das micropartículas, que apresentaram uma diminuição da área superficial e do volume de poros em relação ao núcleo. A liberação in vitro do fármaco ( $\mathrm{pH} 5,0$ e 7,4) mostrou eficiência de dissolução de 34\% e 78\% (núcleo), 74\% e 83\% (mistura física), e $58 \%$ e $85 \%$ (micropartículas nanorrevestidas), respectivamente. A modelagem matemática mostrou os modelos biexponencial ( $\mathrm{pH} 5,0)$ e monoexponencial $(\mathrm{pH} 7,4)$ como aqueles que melhor descreveram os perfis de liberação. Na tolerância digestiva, os índices lesionais totais foram de 156,1 \pm 48,5 para a solução do diclofenaco sódico, de 132,4 \pm 45,7 para o núcleo, de 109,1 $\pm 35,8$ para a mistura física e de 29,9 \pm 12,1 para as micropartículas, demonstrando o efeito protetor destas micropartículas frente à toxicidade do diclofenaco. Esta estratégia de revestimento apresenta um emprego potencial no desenvolvimento de sistemas de administração oral de fármacos.
\end{abstract}

This work reports the preparation and characterization of polymeric nanostructure-coated diclofenacloaded microparticles. After spray-drying, powders presented $80 \%$ of yield and encapsulation efficiency of $83 \%$. SEM analyses showed nanostructures adsorbed onto the surface of microparticles presenting surface area (BET) and pore volumes (BJH) $\left(83 \mathrm{~m}^{2} \mathrm{~g}^{-1}, 0.10 \mathrm{~cm}^{3} \mathrm{~g}^{-1}\right)$ smaller than the uncoated-core (163 $\left.\mathrm{m}^{2} \mathrm{~g}^{-1}, 0.25 \mathrm{~cm}^{3} \mathrm{~g}^{-1}\right)$. In vitro drug release experiments at $\mathrm{pH} 5.0$ and 7.4 showed dissolution efficiencies of $34 \%$ and $78 \%$ (uncoated-core), $74 \%$ and $83 \%$ (physical mixture of raw materials), and $58 \%$ and $85 \%$ (nanostructure-coated microparticles), respectively. Mathematical modeling of the dissolution profiles fitted a biexponential model at $\mathrm{pH} 5.0$ and a monoexponential model at $\mathrm{pH}$ 7.4. Regarding the digestive tolerance experiments, the total lesional indexes were $156.1 \pm 48.5$ for sodium diclofenac aqueous solution, $132.4 \pm 45.7$ for uncoated-core, $109.1 \pm 35.8$ for physical mixture and $29.9 \pm 12.1$ for microparticles showing a protective effect of these microparticles against the mucosal diclofenac damage. This strategy of coating presents a potential use for oral administration of drugs.

Keywords: diclofenac, polymer, nanostructure-coating, microparticles, gastrointestinal tolerance

\section{Introduction}

In the pharmaceutical field, coating techniques are largely employed in order to produce sustained release dosage forms for oral administration, as well as to protect the drug from inactivation or the gastrointestinal mucosa against drug damage. In general coating processes are carried out on single unit dosage forms, as tablets or capsules, after their production. ${ }^{1}$

*e-mail: nanoc@farmacia.ufrgs.br
Several reports in the literature show that the coating of particles presents more advantages compared to the coating of unit dosage forms. ${ }^{2-4}$ These advantages are given by the more reproducible gastrointestinal transport, higher bioavailability, more uniformly spread out in the gastrointestinal tract and reduction of the local irritation. ${ }^{3,5}$ The main useful methods in particle coating are air suspension (Wurster process, fluid-bed dryer) centrifugation, spray-drying, coacervation (aqueous phase separation) and interfacial polymerization. ${ }^{1}$ Coating systems using organic solvents offer some processing advantages such as low heat of vaporization, stability of water-soluble or moisture- 
sensitive drugs, and short processing time. However, safety precautions, environmental pollution and the economic advantages favor the use of systems using water as solvent. ${ }^{6-10}$

Drug carriers have been developed by several approaches to increase the efficacy and/or to decrease the toxicity of drugs. ${ }^{11-15}$ Regarding oral administration, microparticles were widely proposed to carry drugs in the past 30 years. ${ }^{16}$ In general, these systems consist of polymeric materials in which the drug is dispersed, entrapped, dissolved or adsorbed. ${ }^{11,17}$

An easy method for preparing microparticulate delivery systems is the spray-drying technique which has been successfully employed as described in the literature..$^{5,8,18-21}$ This method is widely used in industrial processes to prepare conventional pharmaceutical or nutritional products. ${ }^{22,23}$ In this way, spray-drying is an important method to develop new microparticulate systems at experimental scale that can allow an easy industrial transposition.

Recently our research group has developed a method to dry nanoparticulate aqueous suspensions by spray-drying. ${ }^{24-}$ ${ }^{27}$ These powders consist of microparticles of silicon dioxide (contanining or not a drug) individually coated by polymeric nanoparticles (contanining or not a drug) (Figure 1). In the past few years we have characterized these new systems in order to understand their organization at a molecular level, as well as their competence to control drug release. ${ }^{9,28-30}$

A

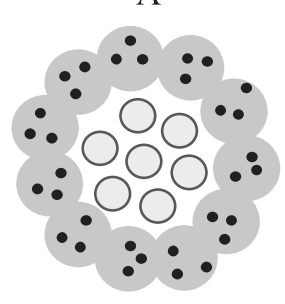

- Drug

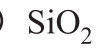

$\mathrm{SiO}_{2}$

Figure 1. Schematic representation of nanostructure-coated microparticles, in which the drug is associated with the organic phase (A) or with the inorganic phase (B).

The polymeric nanoparticles used to coat the inorganic microparticles can be prepared by nanoprecipitation or interfacial deposition of pre-formed polymers, as previously described..$^{9,31-33}$ These methods generally employ an organic phase which is poured into an aqueous phase. The organic solvent is evaporated and the water concentrated by distillation under reduced pressure.

This work reports an approach for the preparation of new nanostructure-coated microparticles by spray-drying from a buffered aqueous suspension. The formulation is based on the use of nanostructured Eudragit $\mathrm{S} 100^{\circledR}$ as a coating material of a core composed by the drug (diclofenac) and silicon dioxide.
The major advantages of this new microparticulate system are the absence of organic solvent either in the preparation of the polymeric nanostructure suspension or in the coating step. Besides, the production of a new material in which each microparticle is individually coated can be achieved. The new formulation was characterized in terms of powder yield, encapsulation efficiency, morphology, in vitro drug release and in vivo gastrointestinal tolerance. Diclofenac was chosen as a model of drug due to its hydrophobic characteristics and its gastrointestinal side-effects (irritation, ulceration and mucosal damage), which allowed to carry out an in vivo experiment to evaluate the effectiveness of the polymeric nanocoating.

\section{Experimental}

\section{Materials}

Diclofenac (sodium salt) was obtained from Sigma (St. Louis, EUA). Eudragit S100 ${ }^{\circledR}$ (EUD), a copolymer of methacrylic acid and methyl methacrylate (in a molar ratio of 1:2) presenting molecular weight in the range of 200000 to $250000 \mathrm{~g} \mathrm{~mol}^{-1}$, was supplied by Almapal (São Paulo, Brazil). Colloidal silicon dioxide (Aerosil 200 ${ }^{\circledR}$ ) was acquired from Degussa (São Paulo, Brazil). All other chemicals and solvents presented pharmaceutical grade and were used as received.

\section{Preparation of free acid form of diclofenac}

An aqueous solution (400 mL) of sodium diclofenac ( $3.0 \mathrm{~g}, 9.43 \mathrm{mmol})$ was acidified with $5 \mathrm{~mol} \mathrm{~L}^{-1} \mathrm{HCl}(5 \mathrm{~mL})$ and the precipitate (free acid form of diclofenac) was filtered and recrystallized from ethanol/water 1:1 (v/v). Colorless crystals were obtained with $90 \%$ of yield and characterized by infrared analysis (FT-IR 8300, Shimadzu, Tokyo, Japan).

IR $v_{\max } / \mathrm{cm}^{-1}: 3322(\mathrm{NH}), 2940$ (br, OH), 1694 (CO), $1587(\mathrm{C}=\mathrm{C}), 1507$ and 1453 (aromatic rings), $1160(\mathrm{C}-\mathrm{O})$.

\section{Preparation of the core}

To obtain the core of the microparticles (uncoated-core), $50 \mathrm{~mL}$ of a diclofenac (free acid) acetone solution $(5.00 \mathrm{mg}$ $\mathrm{mL}^{-1}$ or $\left.0.34 \mathrm{mmol} \mathrm{L}^{-1}\right)$ were mixed with Aerosil $200^{\circledR}(1.5$ g). The acetone was removed under reduced pressure to obtain a solid product. This powder (the core) was maintained in a dessiccator at room temperature for $48 \mathrm{~h}$.

\section{Preparation and characterization of the nanostructure} suspension

A polymeric dispersion was prepared using the EUD $(1.0 \mathrm{~g})$ and phosphate buffer $\mathrm{pH} 7.4(100 \mathrm{~mL})$. This 
suspension was used as coating material for producing polymeric-coated microparticles (MP). The particle size was measured by photon correlation spectroscopy (PCS) after dilution of samples with water (Milli-Q $\left.{ }^{\circledR}\right)$. The scattered light was observed at an angle of $90^{\circ}$ (Brookheaven Instruments, goniometer BI-200M/2.0 version, Holtsville, USA; BI9863 detection system; Laser He-Ne source $35 \mathrm{~mW}, 127$ model, $\lambda=632.8 \mathrm{~nm}$, Spectra Physics, Mountain View, USA).

\section{Preparation of nanostructure-coated microparticles}

The core material $(1.5 \mathrm{~g})$ was carefully milled in a mortar for $10 \mathrm{~min}$, and dispersed into $50 \mathrm{~mL}$ of the nanostructure suspension under magnetic stirring at room temperature. The mixture was fed into a mini-spray-dryer Büchi $190^{\circledR}$ (Flawil, Switzerland) with a two-component nozzle and co-current flow (Air flow rate: $500 \mathrm{NL} \mathrm{h}^{-1}$; atomizing air pressure: 2 bar). The inlet air temperature and feeding spray rate varied according to preliminary experiments. The powder was designed MP. A physical mixture consisting of Aerosil $200^{\otimes}(1.27 \mathrm{~g})$ and sodium diclofenac $(0.72 \mathrm{mmol})$ was prepared as control.

\section{Determination of yield}

The yield of the powder was calculated (equation 1) as the ratio between the experimental weight of product and the sum of the weights of all components, discounting the initial weight of water in the buffer solution used to prepare the nanotructure aqueous suspension.

$$
\text { Yield }(\%)=\frac{W_{\text {product }}}{W_{\text {susp }}+W_{\text {core }}-W_{H_{2} \mathrm{O}}} \times 100
$$

Where:

$W_{\text {product }}=$ Experimental weight of powder $(\mathrm{g})$

$W_{\text {susp }}=$ Weight of all components of nanostructure aqueous suspension $(\mathrm{g})$

$W_{\text {core }}=$ Weight of core $(\mathrm{g})$

$W_{\mathrm{H}_{2} \mathrm{O}}^{\text {core }}=$ Weight of water in the suspension $(\mathrm{g})$

\section{Encapsulation efficiency}

The powders (cores and polymeric nanostructurecoated microparticles) were dispersed in phosphate buffer pH 7.4 for $60 \mathrm{~min}$, at room temperature, followed by the centrifugation of the mixtures. Then, the supernatants were appropriately diluted with mobile phase and filtered through a hydrophilic membrane (GVWP, $0.22 \mathrm{~mm}$, Millipore). The samples were analyzed by HPLC. The chromatographic system consisted of a Lichrospher ${ }^{\circledR}$ column RP 18 (250 x 4 mm, Merck, Darmstadt, Germany) and a Perkin Elmer instrument (200 Series, Shelton, EUA). The mobile phase consisted of acetonitrile/pH 5.0 phosphate buffer (60:40, v/v) with a flow rate of $1.2 \mathrm{~mL}$ $\mathrm{min}^{-1}$. The volume injected was $20 \mu \mathrm{L}$. Diclofenac was detected at $280 \mathrm{~nm}$.

The encapsulation efficiency of each formulation was calculated by the correlation of the theoretical and the experimental diclofenac concentrations and expressed as percentages (\%) (equation 2). Experiments were made in triplicate.

$E E(\%)=\frac{C}{C_{t}} x 100$

Where:

$E E=$ Encapsulation efficiency $(\%)$

$C=$ Experimental (HPLC) concentration of drug (mg $\mathrm{mL}^{-1}$ )

$C_{t}=$ Theoretical concentration of drug $\left(\mathrm{mg} \mathrm{mL}^{-1}\right)$ after dispersion of powder in phosphate buffer $(\mathrm{pH} 7.4)$

The HPLC method was validated according to the following characteristics: linearity, range, precision, accuracy and specificity. ${ }^{34,35}$ This method is linear $\left(\mathrm{r}^{2}=1\right)$ in the range of $3-15 \mu \mathrm{g} \mathrm{mL}^{-1}$, accurate $(100 \pm 6 \%-102 \pm$ $3 \%$ ) and precise (standard deviation: $1.25-1.57 \%$ and 1.47 and $1.91 \%$, for repeatability and intermediate precision, respectively). Experiments were carried out in triplicate for three consecutive days.

\section{Morphological characterization - Scanning electron microscopy}

The uncoated-core and the MP formulation were examined under scanning electron microscopy (SEM) (Jeol Scanning Microscope, JSM-5800, Tokyo, Japan) at different magnifications between 1,000 and 90,000 times. Samples were analyzed after they had been gold sputtered (Jeol Jee 4B SVG-IN, Tokyo, Japan).

\section{Surface area and pore size distribution}

The nitrogen adsorption-desorption isotherms of previous degassed organic-inorganic solids, under vacuum at $40{ }^{\circ} \mathrm{C}$, were determined at liquid nitrogen boiling point in a home-made volumetric apparatus, using nitrogen as probe. The apparatus was frequently checked with an alumina Aldrich standard reference (150 mesh, $5.8 \mathrm{~nm}$ and $\left.155 \mathrm{~m}^{2} \mathrm{~g}^{-1}\right)$. The specific surface areas of powders were determined by the BET multipoint technique $^{36}$ and the pore size distribution was obtained using the BJH method. ${ }^{37}$ 
In vitro drug release

The in vitro drug release experiments were carried out using a flow-through cell technique. The apparatus consisted of recycling flow-through cells (Desaga, Wiesloch, Germany) connected to a peristaltic pump

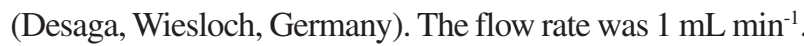
Release experiments were carried out at $37 \pm 0.5^{\circ} \mathrm{C}$, using dissolution media at $\mathrm{pH} 5.0$ or $\mathrm{pH} 7.4$ (phosphate buffer). At $\mathrm{pH}$ 5.0, only the diclofenac can dissolve, while at $\mathrm{pH}$ 7.4 both drug and polymer can be dissolved due to their $\mathrm{p} K_{\mathrm{a}}$ values. An exact amount of each powder (equivalent to $6.80 \times 10^{-3} \mathrm{mmol}$ of diclofenac) was placed in each cell. Samples were collected at predetermined intervals, diluted (if necessary), and filtered through a hydrophilic membrane (GVWP, $0.22 \mu \mathrm{m}$, Millipore) for HPLC analyses. Experiments were carried out in triplicate.

The dissolution profiles of diclofenac from microparticles were analyzed by: a) ANOVA-based method (point to point comparison); b) Model-dependent methods, (MicroMath Scientist ${ }^{\circledR}$ software, Salt Lake City, USA); and c) Modelindependent method (dissolution efficiency - DE).

\section{In vivo gastrointestinal tolerance}

Experiments were carried out on male Wistar rats, weighing between 250 and 350 g (Biotério Central, UFRGS, Porto Alegre, Brazil). The animals were divided into groups of ten. The groups were kept in separate cages and the rats were allowed to eat and drink ad libitum. The sodium diclofenac aqueous solution and diclofenac-loaded formulations (uncoated-core, physical mixture of raw materials and MP) were given at a dose of $20 \mathrm{mg} \mathrm{kg}^{-1}$ by the intragastric route. The solution and formulations were administered daily for 3 consecutive days. Twenty-four hours after the third administration, the rats were decapitated following laparatomy. In order to quantify gastrointestinal lesions, the stomach was opened along the greater curvature and the intestine (duodenum, jejunum and ileum) was slit open opposite the attached mesenteric tissue. The organs were washed with normal saline $(0.9 \% \mathrm{NaCl})$ to remove luminal contents and the mucosal surfaces were examined. Lesions were scored for each organ according to an arbitrary scale as previously reported..$^{38}$ The mean organ lesional index was calculated for each organ in all animals of the same group and then dividing the total lesional score sum by the number of animals in each group. Statistical comparisons of the gastrointestinal lesional indexes in rats were conducted using the Kruskal-Wallis analysis of variance by rank.

\section{Results and Discussion}

\section{Preparation and characterization of nanostructure- coated microparticles}

The core of microparticles consisted of diclofenac (free acid) and silicon dioxide. The uncoated-core, a powder, was obtained with a yield of approximately $100 \%$ by an evaporation process and presented an encapsulation efficiency of $91 \pm 4 \%$.

Eudragit $\mathrm{S} 100^{\circledR}$ is generally used to produce modified release systems due to its gastric resistance. ${ }^{39}$ In this work, the nanostrutured suspension of Eudragit S100 ${ }^{\circledR}$ was proposed for coating the diclofenac-loaded silicon dioxide core. The nanostructure suspension presented nanometric particle diameters in the range of 50-400 $\mathrm{nm}$ determined by dynamic light scattering.

The nanostructure-coated microparticles were prepared by spray-drying in one step after dispersing the diclofenacloaded core into the nanostructured Eudragit S100 ${ }^{\circledR}$ aqueous suspension. The yield of the process was $80 \%$ and the encapsulation efficiency was $83 \pm 1 \%$.

By SEM the morphological analyses of the uncoatedcore showed irregular shaped microparticles presenting surface similar to the pure spray-dried silicon dioxide. ${ }^{9}$ On the other hand, the MP powder showed nanostructures adsorbed on the surface of microparticles (Figure 2) in a wide size distribution. The morphological data corroborate well the polydispersion detected in the nanostructure suspension before spray-drying.

The surface area and the pore size distribution were determined by BET and BJH methods. ${ }^{37,38}$ The uncoatedcore presented a surface area of $163 \mathrm{~m}^{2} \mathrm{~g}^{-1}$ (Table 1), while the commercial silicon dioxide showed a value of 214 $\mathrm{m}^{2} \mathrm{~g}^{-1}$. The pores of the Aerosil $200^{\circledR}$ are resultant from the agglomeration of its primary particles. In this way, the presence of the drug in the macropores of silicon dioxide can explain the decrease in the surface area value for the uncoated-core.

Comparing to silicon dioxide, the MP powder also presented a decrease in the surface area (Table 1 ). The value of $83 \mathrm{~m}^{2} \mathrm{~g}^{-1}$ determined for MP could be explained by a partial reduction in the nitrogen accessibility to the pores. The polymeric coating produced a decrease in the microparticles surface area compared to the uncoated-core. The pore volume values were $0.31 \mathrm{~cm}^{3} \mathrm{~g}^{-1}, 0.25 \mathrm{~cm}^{3} \mathrm{~g}^{-1}$, and $0.10 \mathrm{~cm}^{3} \mathrm{~g}^{-1}$ for commercial silicon dioxide, uncoatedcore and MP, respectively. These values showed that the presence of the organic polymer (Eudragit $S 100^{\circledR}$ ) reduced the surface area and the pore volume of microparticles. The pore size distribution showed a slight decrease in the 
a)

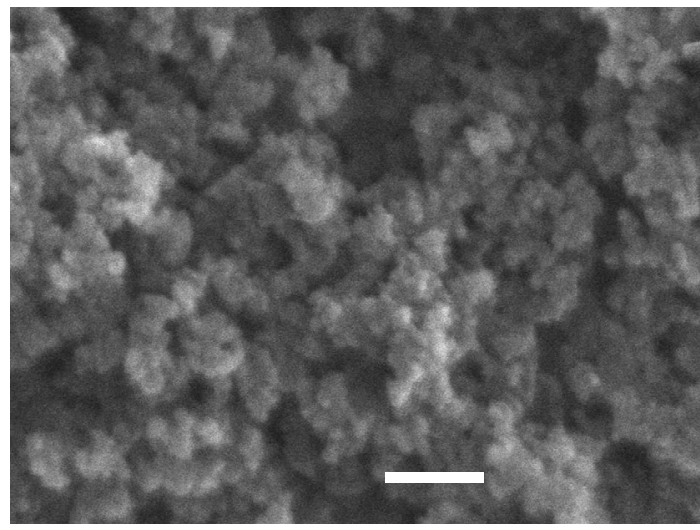

b)

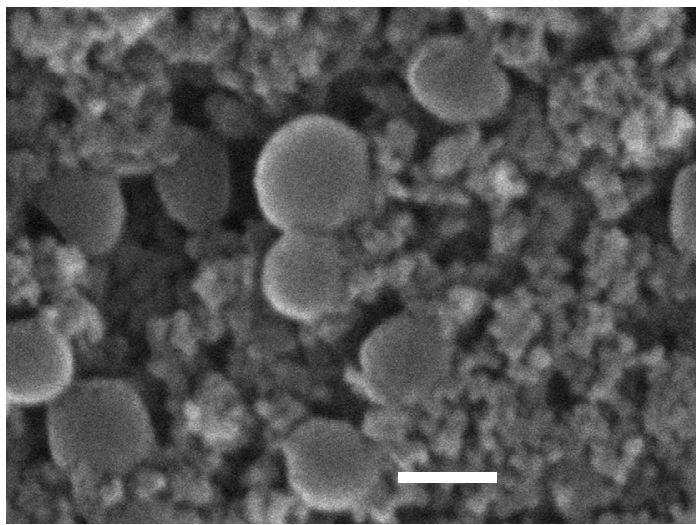

Figure 2. SEM micrographs $($ bar $=200 \mathrm{~nm}$ ) of (a) surface of a particle from the uncoated-core and (b) surface of a particle from the nanostructure-coated microparticles (MP).

mesoporous region (pores between 2 and $50 \mathrm{~nm}$ ) for the MP (Figure 3). These results suggest that the drug-loaded silicon dioxide (uncoated-core) was coated by the nanostructured polymer after spray-drying.

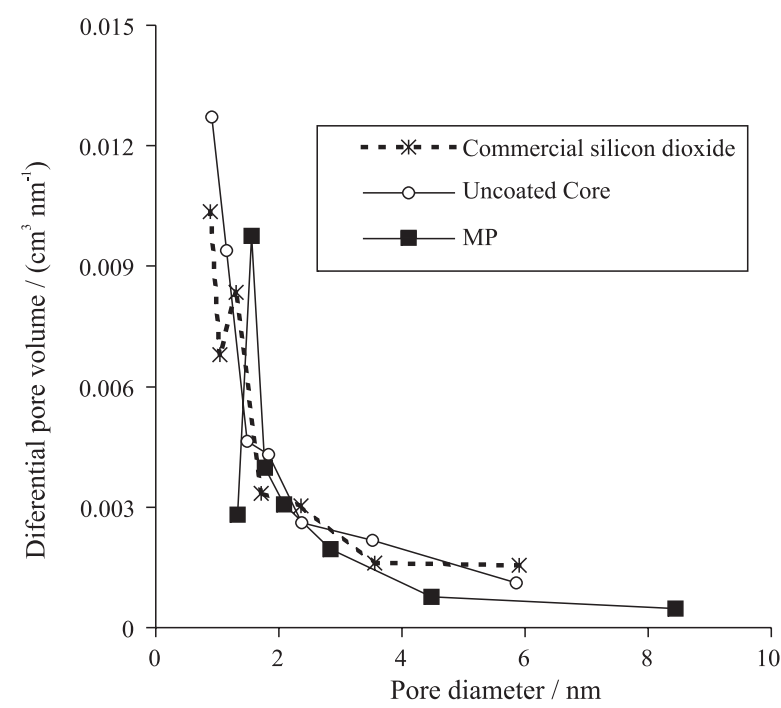

Figure 3. Pore size distribution of commercial silicon dioxide (Aerosil $200^{\circledR}$ ), uncoated-core and nanostructure-coated microparticles (MP) obtained by BJH method.
Table 1. Surface area and pore volume of nanostructure-coated microparticles (MP), uncoated-core, and commercial silicon dioxide (Aerosil 200 ${ }^{\circledR}$ )

\begin{tabular}{lcc}
\hline Sample & Surface area $\left(\mathrm{m}^{2} \mathrm{~g}^{-1}\right)$ & Pore volume $\left(\mathrm{cm}^{3} \mathrm{~g}^{-1}\right)$ \\
\hline MP & 83 & 0.10 \\
Uncoated-core & 163 & 0.25 \\
Aerosil 200 & 214 & 0.31 \\
\hline
\end{tabular}

\section{In vitro drug release}

In order to characterize the in vitro release profile of this new formulation, experiments were carried out comparing MP, uncoated-core and physical mixture of raw materials using phosphate buffer at $\mathrm{pH} 5.0$ and 7.4 as media (Figures 4 and 5, respectively). At pH 5.0, the uncoatedcore presented a diclofenac release of $17 \%$ after $60 \mathrm{~min}$, and $53 \%$ after $360 \mathrm{~min}$. On the other hand, the drug was released $51 \%$ after $60 \mathrm{~min}$, and $101 \%$ after $360 \mathrm{~min}$ from physical mixture, and $44 \%$ and $75 \%$ from MP, respectively. The dissolution efficiencies at $\mathrm{pH} 5.0$ (Table 2) were $34 \pm$ $8 \%$ (uncoated-core), $74 \pm 4 \%$ (physical mixture), and $58 \pm$ $6 \%$ (MP).

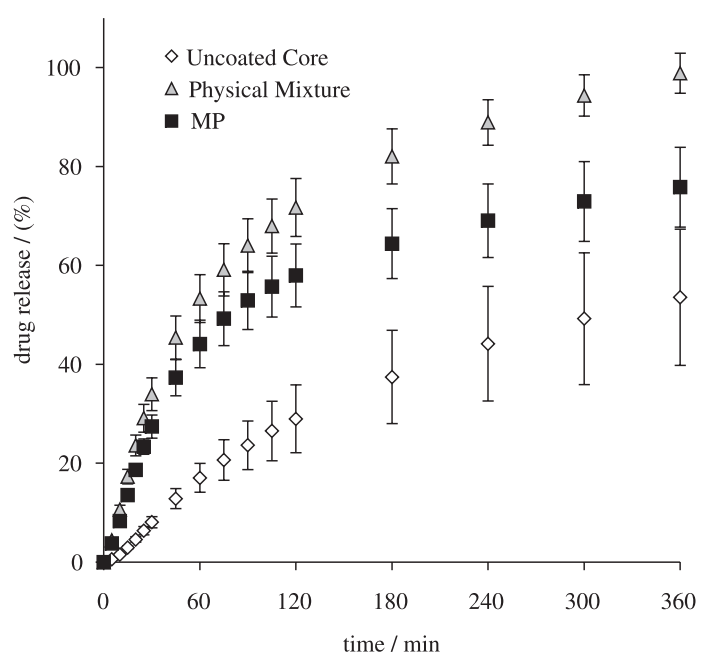

Figure 4. Release profiles (phosphate buffer pH 5.0) of diclofenac from the uncoated-core, physical mixture, and nanostructure-coated microparticles (MP).

At pH 7.4 Eudragit ${\mathrm{S} 100^{\circledR}}^{\circledR}$ dissolves ${ }^{39}$ and the release of the drug from MP could follow two mechanisms:(i) drug diffusion due to the diclofenac dissolution after carboxylate formation (diclofenac $\mathrm{p} K_{\mathrm{a}}$ is 3.8 at $25{ }^{\circ} \mathrm{C}{ }^{40}$ ) and (ii) polymer erosion after its salt formation and dissolution. The drug release was $100 \%$ from MP after 60 min. The dissolution efficiencies (Table 2) were $78 \pm 1 \%$ for the uncoated-core, $84 \pm 1 \%$ for physical mixture and $84 \pm 3 \%$ for MP. At this $\mathrm{pH}$, it was not observed difference $(p>0.05)$ in the dissolution efficiency between MP and physical mixture. However, the uncoated-core showed a slightly lower dissolution efficiency $(p>0.05)$ than the 
Table 2. Dissolution efficiency determined for the uncoated-core, physical mixture, and nanostructure-coated microparticles (MP) at pH 5.0 and 7.4

\begin{tabular}{lcc}
\hline \multirow{2}{*}{ Formulation } & \multicolumn{2}{c}{ Dissolution efficiency (\%) } \\
\cline { 2 - 3 } & $\mathrm{pH} 5.0$ & $\mathrm{pH} 7.4$ \\
\hline Uncoated-core & $34 \pm 8$ & $78 \pm 1$ \\
Physical mixture & $74 \pm 4$ & $84 \pm 1$ \\
MP & $58 \pm 6$ & $84 \pm 3$ \\
\hline
\end{tabular}

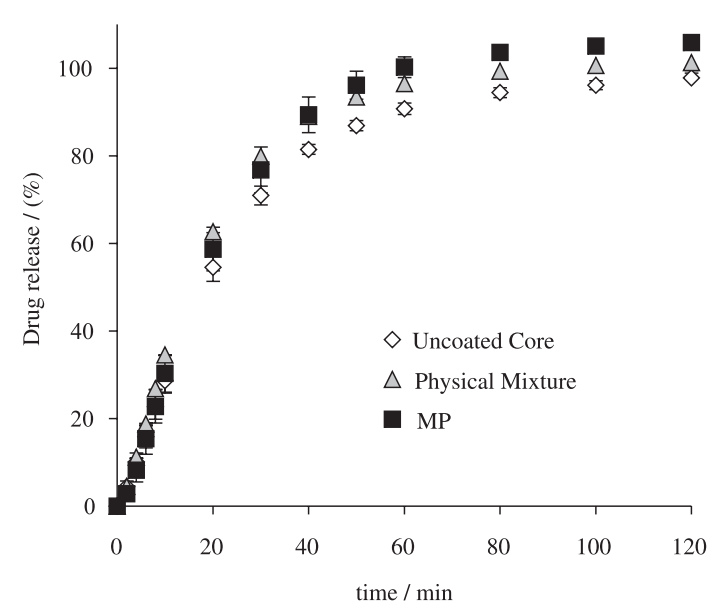

Figure 5. Release profiles (phosphate buffer $\mathrm{pH}$ 7.4) of diclofenac from the uncoated-core, physical mixture, and nanostructure-coated microparticles (MP).

other formulations. The presence of salts in the MP formulation could promote a faster drug release than the drug release observed from the uncoated-core.

Mathematical modeling was used to analyze the dissolution profiles (Table 3 ). The selection of model was based on the best correlation coefficient, the best model selection criteria (MSC) and the best graphic adjustment. At $\mathrm{pH}$ 5.0, the biexponential model fitted the dissolution data for the uncoated-core $\left(k=0.0078 \mathrm{~min}^{-1} ; k^{\prime}=0.0001\right.$ $\left.\min ^{-1}\right)$, as well as for physical mixture $\left(k=0.0337 \mathrm{~min}^{-1}\right.$; $\left.k^{\prime}=0.0080 \mathrm{~min}^{-1}\right)$ and MP $\left(k=0.0219 \mathrm{~min}^{-1} ; k^{\prime}=0.0018\right.$ $\left.\mathrm{min}^{-1}\right)$. The percentage of drug in each sample that contributed for the burst phase release was $40 \%$ (uncoatedcore), $32 \%$ (physical mixture) and 55\% (MP). In the physical mixture sample, the small particles of drug were responsible for its burst release, whereas, in the other samples (uncoated-core and MP), the drug burst release was a consequence of free and/or adsorbed drug.

At pH 7.4 the monoexponential model fitted better the dissolution data than the other models (Table 3). The observed rate constant values were $k=0.0380 \mathrm{~min}^{-1}$ (uncoated-core), $k=0.0497 \mathrm{~min}^{-1}$ (physical mixture), and $k=0.0447 \mathrm{~min}^{-1}$ (MP). In this medium, modeling the dissolution profiles did not provide a resolution to determine burst and sustained phases. Comparing the uncoated-core and the MP, the difference of diclofenac
Table 3. Model-dependent approaches used for mathematical modeling

\begin{tabular}{lll}
\hline Approach & Method & Equation ${ }^{\mathrm{a}, \mathrm{b}, \mathrm{c}}$ \\
\hline Model-dependent & Zero-order & $\%$ diss $=\mathrm{kt}$ \\
& First-order & $\%$ diss $=100\left(1-\mathrm{e}^{-\mathrm{kt}}\right)$ \\
& Biexponencial & $\%$ diss $=100\left[1-\left(\mathrm{A} \cdot \mathrm{e}^{-\mathrm{kt}}+\mathrm{B} \cdot \mathrm{e}^{-\mathrm{k}^{\mathrm{t} t}}\right)\right.$ \\
& Weibull & $\%$ diss $=100\left[1-\mathrm{e}^{-(\mathrm{t} \mathrm{Td}) \beta}\right]$ \\
& Higuchi & $\%$ diss $=\mathrm{kt}^{0.5}$ \\
\hline
\end{tabular}

a \% diss: percentage dissolved at time $t .{ }^{\mathrm{b}} \mathrm{k}$ and $\mathrm{k}^{\prime}$ : dissolution rate constants. ${ }^{c} \mathrm{~T}_{\mathrm{d}}$ : time at which $63.2 \%$ of the material is dissolved; $\beta$ : shape parameter.

dissolution rates could be explained by the presence of phosphate buffer in the aqueous Eudragit S100 ${ }^{\circledR}$ suspension that was used to prepare the MP.

\section{In vivo gastrointestinal tolerance}

All formulations (sodium diclofenac aqueous solution, uncoated-core, physical mixture and MP) presented a low lesional index for the stomach $(0.1 \pm$ 0.3 for sodium diclofenac aqueous solution, $0 \pm 0$ for uncoated-core, $0.7 \pm 1.5$ for physical mixture and $0 \pm 0$ for MP), which did not differ significantly among the groups ( $<$ 0.05) (Figure 6). These results correlate well with those reported for non-steroidal anti-inflammatory drugs using the same animal model. ${ }^{27,29,38,41}$ Rats are more sensitive to intestinal ulcerations than other mammals, including human beings, due to high enterohepatic recirculation. ${ }^{42}$

Regarding the duodenum (Figure 6), the lesional indexes were $3.6 \pm 2.1$ for sodium diclofenac aqueous solution, $0.5 \pm 0.7$ for uncoated-core, $4.0 \pm 3.0$ for

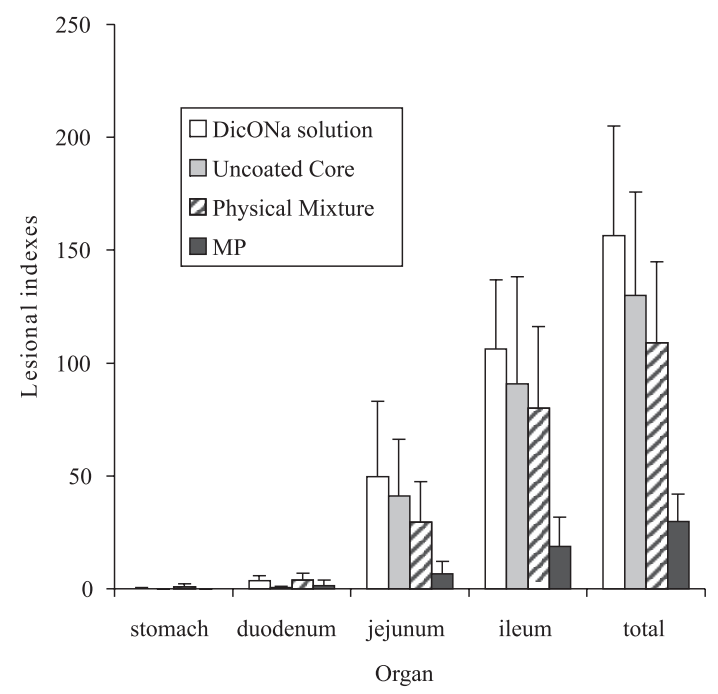

Figure 6. Mean organ lesional index following three consecutive daily doses of $20 \mathrm{mg} \mathrm{kg}^{-1}$ of sodium diclofenac aqueous solution (DicONa), uncoated-core, physical mixture, and nanostructurecoated microparticles (MP). 
physical mixture and $1.4 \pm 2.4$ for MP. All these values depicted few ulceration in this organ. Lesional indexes in the jejunum were $49.7 \pm 33.5$ for sodium diclofenac aqueous solution, $41.1 \pm 25.1$ for uncoated-core, $29.5 \pm$ 18.0 for physical mixture and $6.6 \pm 5.5$ for MP. The MP presented a mucosal protective effect $(\mathrm{p}<0.05)$. These results showed that the drug-loaded silicon dioxide (uncoated-core) was not able to protect the intestinal mucosa without polymeric coating. However, in our previous work, ${ }^{27}$ the diclofenac-loaded silicon dioxide has presented a protective effect of intestinal mucosa. The different behavior of these formulations prepared without nanostructure suspension or polymeric nanoparticles can be explained by the different drug concentration used in the present work, which is higher $(0.5: 3.0, \mathrm{~m} / \mathrm{m})$ than in the previous report $(0.1: 3.0, \mathrm{~m} /$ $\mathrm{m})$. Finally, the lesional indexes in the ileum were 106.1 \pm 30.7 for sodium diclofenac aqueous solution, $90.8 \pm$ 47.5 for uncoated-core, $79.9 \pm 36.3$ for physical mixture and $18.9 \pm 12.8$ for MP. The results observed for the ileum are similar to those recorded in the jejunum. Comparing all formulations, the MP presented a mucosal protective effect $(\mathrm{p}<0.05)$.

The total lesional indexes (Figure 6) calculated by the sum of the partial lesional indexes were $156.1 \pm 48.5$ for sodium diclofenac aqueous solution, $132.4 \pm 45.7$ for uncoated-core, $109.1 \pm 35.8$ for physical mixture and 29.9 \pm 12.1 for MP.

In conclusion, the nanostruture-coated microparticles were produced with excellent yield and encapsulation efficiency. Additionally, the morphological analyses suggested that the drug loaded core was coated by the nanostructured polymer producing the nanostructurecoated microparticles. Corroborating with these analyses, the drug release profiles and the gastrointestinal tolerance evaluation have showed the advantages of the new formulation over the simple mixture of raw materials. This new powder has showed a protective effect against the mucosal diclofenac damage in rats, suggesting that this strategy of coating presents a potential use for oral administration of drugs.

\section{Acknowledgments}

RCRB thanks Capes for his research grant. The authors thank the financial support of FAPERGS, CNPq and Rede de Nanobiotecnologia/CNPq/MCT.

\section{References}

1. Lieberman, H. A.; Lachman, L.; Pharmaceutical Dosage Forms: Tablets, $4^{\text {th }}$ ed., Marcel Decker: New York, 1982, vol. 3.

2. Hasan, M.; Najib, N.; Suleiman, M.; El-Sayed, Y.; Abdel-Hamid, M.; Drug Dev. Ind. Pharm. 1992, 18, 1981.

3. Hosny, E. A.; El-Mahrouk, G. M.; Gouda, M. W.; Drug Dev. Ind. Pharm. 1998, 24, 661.

4. Walter, K.; Von Nieciecki, A.; Arzneim. Forschung 2001, 51, 643.

5. Palmieri, G. F.; Bonacucina, G.; Di Martino, P.; Martelli, S.; Drug Dev. Ind. Pharm. 2001, 27, 195.

6. Lin, S. ; Kao, Y.; Pharm. Res. 1991, 8, 919.

7. Obara, S.; McGinity, J. W.; Int. J. Pharm. 1995, 126, 1.

8. Palmieri, G. F.; Bonacucina, G.; Di Martino, P.; Martelli, S.; J. Microencapsulation 2002, 19, 111.

9. Beck, R. C .R.; Pohlmann, A. R.; Guterres, S. S.; J. Microencapsulation 2004, 21, 499.

10. Lecomte, F.; Siepmann, J.; Walther, M.; Macrae, R. J.; Bodmeier, R.; J. Control. Rel. 2004, 99, 1.

11. Benita, S.; Microencapsulation: Methods and Industrial Applications, Marcel Decker: New York, 1996.

12. He, P.; Davis, S. S.; Illum, L.; Int. J. Pharm. 1999, 187, 53.

13. Schaffazick, S. R.; de Freitas, L. L.; Pohlmann, A. R.; Guterres, S. S.; Quim. Nova 2003, 26, 726.

14. Brannon-Peppas, L.; Int. J. Pharm. 1995, 116, 1.

15. Couvreur, P.; Barratt, G.; Fattal, E.; Legrand, P.; Vauthier, C.; Crit. Rev. Ther. Drug Carrier Syst. 2002, 19, 99.

16. Freiberg, S.; Zhu, S.S.; Int. J. Pharm. 2004, 282, 1.

17. Wan, L. S.; Heng, P. W. S.; Chia, C. G. H.; Drug Dev. Ind. Pharm. 1992, 18, 997.

18. Bodmeier, R.; Chen H.; J. Pharm. Pharmacol. 1988, 40, 754.

19. Conte, U.; Conti, B. B.; Giunchedi, P.; Maggi, L.; Drug Dev. Ind. Pharm. 1994, 20, 235.

20. Palmieri, G. F.; Wehrle, P.; Stamm, A.; Drug Dev. Ind. Pharm. 1994, 20, 2859.

21. Huang, Y. C.; Chiang, C. H.; Yeh, K. M.; J. Microencapsulation 2003, 20, 247.

22. Broadhead, J.; Edmond Rouan, S. K.; Rhodes, C. T.; Drug Dev. Ind. Pharm. 1992, 18, 1169.

23. Oneda, F.; Ré, M. I.; Powder Technol. 2003, 130, 377.

24. Guterres, S. S.; Pohlmann, A. R.; Dalla-Costa, T.; Bassani, V. L.; Muller, C. R.; Br PI 9906081-7, 1999.

25. Guterres, S. S.; Weiss, V.; Lucca Freitas, L.; Pohlmann, A. R.; Drug Delivery 2000, 7, 195.

26. Müller, C. R.; Bassani, V. L.; Pohlmann, A. R.; Michalowski, C. B.; Petrovick, P. R.; Guterres, S. S.; Drug Dev. Ind. Pharm. 2000, 26, 343. 
27. Guterres, S. S.; Müller, C. R.; Pohlmann, A. R.; Dalla Costa, T.; STP Pharma Sci. 2001, 11, 229.

28. Pohlmann, A. R.; Weiss, V.; Mertins, O.; Pesce da Silveira, N.; Guterres, S. S.; Eur. J. Pharm. Sci. 2002, 16, 305.

29. Raffin, R. P.; Obach, E. S.; Mezzalira, G.; Pohlmann, A. R.; Guterres, S. S.; Acta Farm. Bonaerense 2003, 22, 163.

30. Müller, C. R.; Schaffazick, S. R.; Pohlmann, A. R.; De Lucca Freitas, L.; Pesce da Silveira, N.; Dalla Costa, T.; Guterres, S. S.; Pharmazie 2001, 56, 864.

31. Fessi, H.; Puisieux, F.; Devissaguet, J.P.; European Patent $0274961,1988$.

32. Calvo, P.; Vila-Jato, J. L.; Alonso, M. J.; J. Pharm. Sci. 1996, 85, 530.

33. Pohlmann, A. R.; Soares, L. U.; Cruz, L.; Pesce da Silveira, N.; Guterres, S.S.; Current Drug Delivery 2004, 1, 103.

34. Validation of Analytical Procedures: Methodology, ICHHarmonised Tripartity Guideline, IFPMA: Geneva, 1996.
35. The United States Pharmacopoeia, $27^{\text {th }}$ ed., The United States Pharmacopoeial Convention, Rockville, USA, 2003.

36. Brunauer, S.; Emmet, P. H.; Teller, E.; J. Am. Chem. Soc. 1938, 60, 309.

37. Barret, E. P.; Joyner, L. G.; Halenda, P. P.; J. Am. Chem. Soc. 1951, 73, 373.

38. Ammoury, N.; Dubrasquet, M.; Fessi, H.; Devissaguet, J.P.; Puisieux, F.; Benita, S.; Clinical Materials 1993, 13, 121.

39. Lamprecht, A.; Yamamoto, H.; Takeuchi, H.; Kawashima, Y.; Eur. J. Pharm. Biopharm. 2004, 58, 37.

40. Chiarini, A.; Tartarini, A.; Fini, A.; Arch. Pharm. 1984, 317, 268.

41. Guterres, S. S.; Fessi, H.; Barratt, G.; Puisieux, F.; Devissaguet, J.P.; Pharm. Res. 1995, 12, 1.

42. Fara, J. W.; Myrback, R. E.; Pharm. Res. 1990, 7, 616.

Received: January 30, 2005 Published on the web: September 22, 2005 